\title{
Homo Virtualis
}

Vol 3, No 2 (2020)

Special Issue: The Coronavirus Disruption to the Digital Landscape: Societal Implications and Interdisciplinary Perspectives
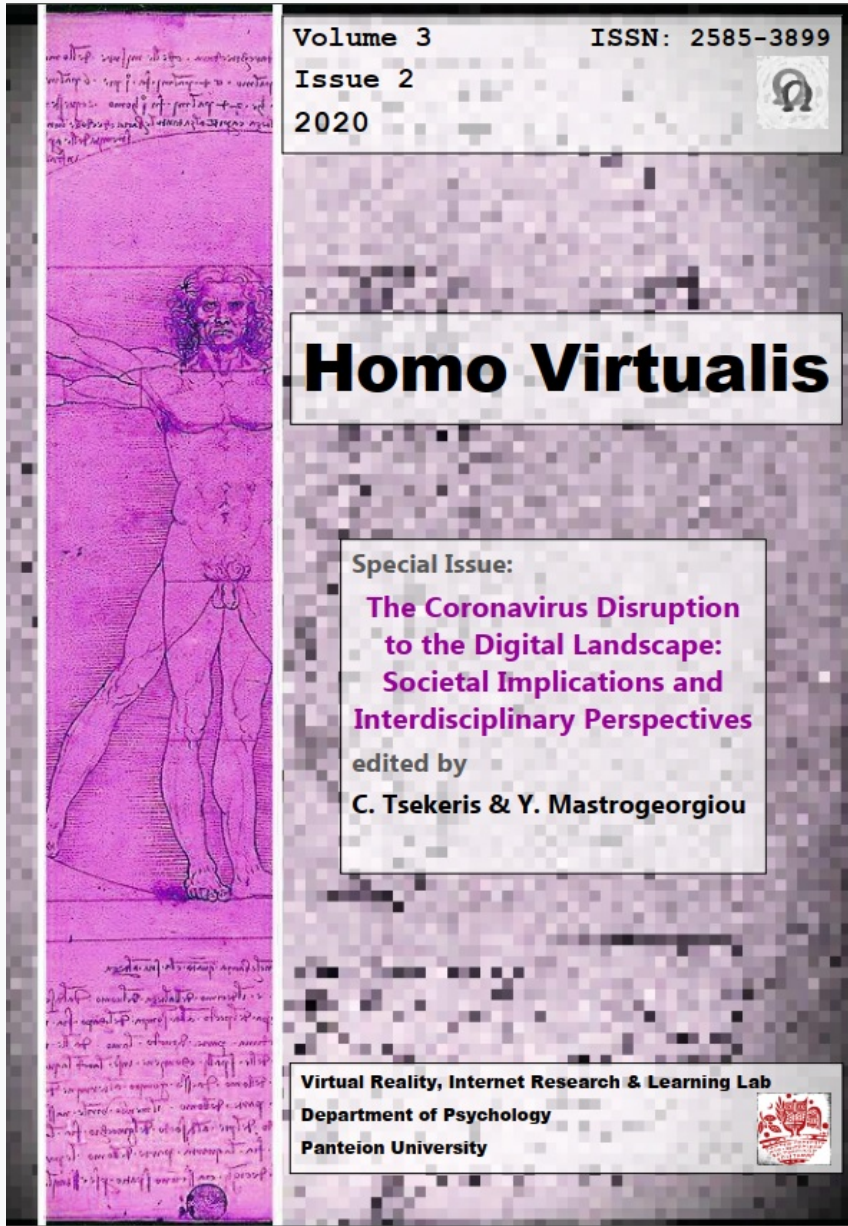

Artificial Intelligence in the post-COVID-19 era

Athanasios Chymis

doi: $10.12681 /$ homvir.25449

Copyright $\odot 2020$, Athanasios Chymis

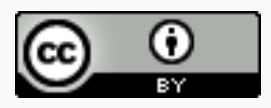

This work is licensed under a Creative Commons Attribution 4.0.

\section{To cite this article:}

Chymis, A. (2020). Artificial Intelligence in the post-COVID-19 era. Homo Virtualis, 3(2), 55-67. https://doi.org/10.12681/homvir.25449 


\title{
Artificial Intelligence in the post-COVID-19 era
}

\author{
Athanasios Chymis ${ }^{1}$
}

\begin{abstract}
Artificial Intelligence (AI) dominates the media and has been the focus of public discourse in the last few years. Since last March, however, COVID-19 makes almost everyday headlines because of its huge impact on our highly globalized world. This article has a dual objective. First, it aims to dissolve common misunderstandings and fears regarding AI. Second, by putting AI's and COVID-19 societal and economic impacts into perspective, it discusses AI applications and research in the post-COVID-19 era. COVID-19 has played a catalytic role in accelerating the use of AI to mitigate the pandemic's devastating effects. It is up to us to use AI in a responsible and ethical way that includes and benefits the whole humanity.
\end{abstract}

Keywords: Artificial Intelligence, COVID-19, Crisis, Opportunities, Responsibility

\section{Introduction}

While Artificial Intelligence (AI) is a relatively recent term coined in 1955 by John McCarthy (Gurkaynak et al., 2016; Floridi \& Cowls, 2019), a Stanford computer and cognitive science professor, it is a very old concept. Greek mythology has very interesting references to automatons ${ }^{2}$ (today we would call them robots) made either by the ancient god of fire, Hephaestus, or the famous mythical Athenian craftsman, Daedalus. This is indicative of the strong imagination people have had, as well as of

\footnotetext{
${ }^{1}$ Senior Research Fellow, Centre of Planning and Economic Research (KEPE). E-mail: achymis@kepe.gr

${ }^{2}$ https://www.greeklegendsandmyths.com/automatons.html
} 
their strong will to make machines that could assist them in their everyday labor since ancient times.

Like all human creations and inventions, AI does not come without negative aspects. Consequently, feelings of desire and fear coexist regarding AI. A lot of research focuses on the potential positive and negative effects of AI (Acemoglu \& Autor, 2012; Acemoglu \& Restpero, 2015; Arntz et al., 2017; Brynjolfsson \& Mitchell, 2017; Sachs \& Kotlikoff, 2012; Stanford report, 2016, to name a few). At the same time, we all have felt the serious disruptive effects COVID-19 has casted over our socio-economic lives. Scientists warn that the vaccines currently developed and tested do not guarantee an immediate return to normalcy (Cimons, 2020). AI has been affected by and affects COVID-19 (Laguarta et al., 2020; Rao \& Butterfield, 2020). It is accelerated dramatically not only to support work from home but mostly to help humanity to combat COVID-19 (Holland, 2020; Nguyen, 2020).

The purpose of this article is twofold. First, it aims to dissolve common misunderstandings and major fears regarding AI. Second, it puts AI's societal and economic impacts into perspective and discusses the impacts of both AI and COVID19 on human societies, as well as how the one affects the other. In what follows, a definition of AI is provided, the major positive and negative impacts of AI are discussed, the disrupting impacts of COVID-19 are presented, and the AI in the postpandemic era is illustrated, while a concluding section wraps up.

\section{Defining AI}

Hollywood movies usually present AI as a dystopian future of intelligent machines that enslave, or even destroy, humanity. Influential figures, such as late Steven Hawking $(2014)^{3}$ and Elon Musk $(2018){ }^{4}$ have also warned against the potential threats from AI, thus contributing in a negative public perception of AI. But what is AI and what are its limits?

Since the term AI appeared back in 1955, many definitions of AI have been stated. A recent definition by Stanford faculty is the following: "Artificial intelligence is that activity devoted to making machines intelligent, and intelligence is that quality that enables an entity to function appropriately and with foresight in its environment" (Stanford report, 2016, 12). Scholars identify several types of AI. Gurkaynak et al. (2016) talk about Artificial Narrow Intelligence (ANI) and Artificial General Intelligence (AGI), while Strelkova and Pasichnyk (2017) add a third type, the Artificial Super Intelligence (ASI). ANI is the type of AI which is technologically reached and in use so far. AGI has not yet been achieved, let alone ASI. AGI and ASI refer to the stage of AI that has reached and overcome human intelligence, and has the ability of thinking in

\footnotetext{
${ }^{3}$ https://www.bbc.com/news/technology-30290540

4 https://www.cnbc.com/2018/03/13/elon-musk-at-sxsw-a-i-is-more-dangerous-than-nuclear-weapons.html
} 
an abstract level, reasoning and learning by experience. Some authors argue that these levels of AI will not be reached (Fjelland, 2020; Dreyfus \& Dreyfus, 1986).

Whether the above prediction comes true or not is left for the future generations to find out. For the time being and for the foreseeable future, the human technological capacity cannot access the level of AGI (Gurkaynak et al., 2016; Fjelland, 2020). All current AI technological advances rest within the area of ANI, from the computer chess player, to driverless autonomous vehicles, to robot assisted surgery. For the moment, humanity is not in danger of extinction from the machines. However, we have to take AI and its potential effects seriously.

\section{AI potential impacts ${ }^{5}$}

There is a plethora of literature on the impacts of AI on several aspects of human life, especially from a labor economics perspective, given that the major concern of humanity is what the effect of AI might be on the substitution of human work. There are studies calculating how many jobs will be lost due to automation and AI (Manyika et al., 2017; Manyika \& Sneader, 2018), but it is difficult to calculate the number of new jobs that will be created in the future (Stewart et al., 2015; Manyika et al., 2017). Manyika et al. (2017) mid-point scenario talks about 400 million jobs lost between 2016 and 2030, or 15\% of the global workforce, while the worst-case scenario raises this number to 800 million (30\% of global workforce).

Despite how disheartening the above forecast may sound, scholars point out that history tell us a more optimistic story (Stewart et al., 2015; Mokyr et al., 2015, Manyika et al., 2017; Manyika \& Sneader, 2018). It seems that fear of progress and resistance to technology is as old as at least the industrial revolution (Mokyr et al., 2015). Specifically, the Luddite movement in the $19^{\text {th }}$ century is the first known example of resistance to technological evolution. The textile workers, the Luddites, thought their jobs were threatened by the first textile machines which were going to substitute the traditional handloom. What happened is that the number of handloom weavers, indeed, declined drastically but, at the same time, textile price decreased due to higher productivity, thus increasing dramatically textiles demand. The new technology revolutionized the textile market and the labor force was rapidly increased along the supply chain of the textile industry (i.e. textile machine workers, supervisors, managers, accountants, etc.) (Mokyr et al., 2015).

The above pattern has been repeated many times since the industrial revolution. Dozens of professions have become obsolete and much more have been created during the last 144 years (Stewart \& Cole, 2015). Yet, the so-called technological unemployment is a persistent concern. Back in 1932, the famous economist J.M. Keynes warned about the possibility of technological unemployment due to increasing productivity (i.e. fewer workers producing more output) (Keynes, 1932). So

\footnotetext{
5 This section draws heavily from Chymis (2020).
} 
far, these concerns have been proved unfounded due to the plethora of new types of jobs and professions created by increased incomes and leisure (Mokyr et al., 2015).

However, the replacement of human by robots and machines raised new concerns regarding other aspects of labor. The literature recognizes that what is more important is the quality of jobs lost and created, as well as the results this job shift will have upon the workers (Fernández-Macías, 2018; Peralta-Alva \& Roitman, 2018). Concerns have been raised over social justice and equality issues (Peralta-Alva \& Roitman, 2018; Zhang, 2019). For example, how societies can reimburse people who lose their jobs due to the digital transformation and they cannot easily be retrained and get another job (e.g. older workers close, or not so close, to retirement). These are issues humanity already faces and has to tackle.

Beyond labor, which is probably the major socioeconomic factor, there are other aspects of human life that AI affects such as education, medicine, entertainment, etc. A comprehensive review by Chui et al. (2018), illustrates all domains of human life where AI can be applied with positive results and a problem-solving capacity. These domains include economic empowerment, health and hunger, education, environment, equality and inclusion, infrastructure, information verification and validation, public and social sector and crisis response (Chui et al., 2018).

\section{COVID-19 disruptive impacts}

All the above-mentioned domains of human life have been affected to a greater or a lesser degree. Millions of people have been forced to work from home, while others lost their job within days if not hours (e.g. in the case of lockdowns) without prior notice. Supply chains were suddenly disrupted causing huge problems in food and other first-need supplies transportation. The decades-long global trend of reducing poverty has been reversed as millions of poor people mostly in developing countries, such as India, lost their city jobs and were forced to move back to their rural hometown where they had migrated from to escape poverty (Economist, 2020b). World Bank (2020a) projects that up to 150 million people will be pushed back into extreme poverty by 2021.

Education is severely affected by COVID-19. Nearly 1.3 billion children were out of school during the many lockdowns of the first wave of the pandemic in Spring 2020 (Nash \& Enyon, 2020). Staying at home has long term effects in their mental and physical health (eating a lot of crisps and sugary drinks, as well as red meat and engaging in less physical activity without interacting with other children) (Economist, 2020d). Moreover, in developing countries effects can be harder, such as missing crucial school meals that parents cannot afford to offer or start working, thus increasing dropouts when the pandemic is over (WHO, 2020).

COVID-19 seems to have created a new type of employment inequality. It has created two kinds of employees, those who are not affected by the pandemic and 
those who are. The first group includes all the public sector employees who mostly get their salaries unchanged, as well as private employees in jobs that were not affected much (financial and banking sector), or even have been positively affected by the pandemic (supermarkets, e-commerce, etc.). The second group includes mainly the leisure and hospitality sector, and many jobs that require physical presence, such as most of the retail, service and manufacturing (Dvorkin, 2020). Most of the affected employees are in the private sector, while all employees of the public sector have not been affected salary-wise. Lockdowns had a dramatic effect on millions of private employees who saw their incomes annihilated within days if not hours. On the contrary, public employees did not see any significant decrease in their salaries either working from home or, in some cases, working much less hours than before.

Another, equally important issue, is the declining quality of democracy (Economist, 2020a). According to a Freedom House special report, 80 countries have experienced a deterioration in their degree of democracy and civil rights protection since the beginning of the pandemic (Repucci \& Slipowitz, 2020). Governments all over the world, from healthy democracies to dictatorships, under the COVID-19 emergency they violate human rights and expand their interventionism. Given than political freedom and economic freedom go together (Friedman, 2002/1962), a related ongoing debate is whether the free market system can find the best solutions to the pandemic, or the strong hand of government should step in. Although countries with coordinated market economies (e.g. Germany, Nordic countries) have suffered less deaths from COVID-19 thanks to the strict measures of lockdowns, it is countries with liberal market economies (e.g. USA, UK, Canada) that most vaccines are currently developed thanks to the innovation incentives the free market system offers (Economist, 2020c).

Of course, the list of COVID-19 disruptive effects does not end here; it would take many pages to describe and present all direct and indirect effects of COVID-19. This article just presents some of the most important effects related to the socioeconomic sphere of human life.

\section{COVID-19 as a catalyst for AI}

COVID-19 has dramatically accelerated AI research and AI applications, including the health sector, in order to intensify the battle against COVID-19 (Jacobs, 2020; Forbes, 2020). The importance of AI as a weapon against COVID-19 is manifested by the inclusion of $\mathrm{AI}$ and COVID-19 in the main agendas of international organizations, such as the World Economic Forum (WEF) ${ }^{6}$. As explained in previous section, AI was

\footnotetext{
https://www.weforum.org/focus/coronavirus-covid-19, https://www.weforum.org/agenda/archive/artificialintelligence-and-robotics
} 
on the rise before COVID-19, but the pandemic has revolutionized AI and digital transformation in general. In other words, the impact of COVID-19 to AI is catalytic.

Digital transformation (DT) is not the same with AI. However, AI can facilitate and enables DT which in turn is a prerequisite for AI (Wuest et al., 2020). Prior to COVID19 , in many countries, all sectors of the economy were undergoing a serious DT. The private sector is a pioneer in DT and AI while the public sector usually lags behind due to lack of incentives (Windrum, 2008). COVID-19 has pushed many countries' (such as Greece's) public sector to incorporate digital technologies and converge with the more digitized private sector (Stone, 2020). Working from home and digital schooling are two very important revolutions the pandemic has caused as a solution to lockdowns. Similarly, e-commerce took off under the regime of general quarantine.

These are AI's responses to some of the effects of the pandemic. Humanity's efforts to combat COVID-19 disastrous impacts spread along the whole specter of human life. Almost every day, the news is full of cases where AI offers solutions. As mentioned before, WEF has a special section on COVID-19 and AI. Visiting this section (see footnote 6) one can read news titles such as: "Robots and chatbots can help alleviate the mental health epidemic," "AI can detect asymptomatic COVID-19 infections in recorded coughs," "This Indian businessman has devised 3 clever AI technologies to keep workers safe from COVID-19," "Here's how your robot coworker could help you deal with stress at work," "These [AI related] 15 innovations are helping us fight COVID-19 and its aftermath;" "Digital diagnosis: why teaching computers to read medical records could help against COVID-19," "How AI is helping combat homelessness in Canada during COVID-19'.

\section{AI in the post-COVID-19 era}

AI is by itself a technological revolution and it is the last one in a series of technological revolutions in the last 250 years (Freeman \& Louçã, 2001): The initial industrial revolution (circa 1770), the steam and railway (ca. 1830), the electricity and engineering in 1875, the oil, automobile and mass production in 1910, the microprocessor in 1970, the internet and the world wide web (www), just a few decades ago, are now followed by $\mathrm{AI}$, the last link in a chain of continuous and accelerating technological breakthroughs (Freeman \& Louçã, 2001; FernándezMacías, 2018).

Like every revolution in the past, AI revolution creates concerns and, to many people, even fear, like the Luddites in late $18^{\text {th }}$ early $19^{\text {th }}$ century. Thankfully, every time the result was a significant improvement of the human condition (Pinker, 2018; McCloskey, 2016). An improvement which led to the decline of global extreme poverty ${ }^{7}$ down to less than $10 \%$ of global population just before the pandemic hit

\footnotetext{
${ }^{7}$ Those who live with less than $\$ 1.90$ per day, according to the WB.
} 
(World Bank, 2020b). Not only that, but also a series of wellbeing indicators, such as access to clean water and sanitary conditions, life expectancy, maternal and newborn mortality, girls' school attendance, etc., have been steadily improving since 1990 (Baldwin, 2016). As Rosling et al. (2018) demonstrate, humanity has been improving with major intervals such as the two world wars, the 1918 flu, etc.- since the last 200 years and continuously since the 1950's.

This of course does not mean that AI (like every revolution before) does not have any negative effects. People who lose their jobs are among the losers of each revolution. However, the interconnected globalized world is now much better placed to deal with all negative aspects of any technological revolutions than it was decades or hundreds of years ago. Without being able to compare the current pandemic with the $1918 \mathrm{flu}^{8}$ pandemic once they are of different origin, namely, the COVID-19 is caused by the new coronavirus whereas the 1918 flu was caused by the influenza viruses (CDC, 2020), it is certain that humanity is now much better equipped to combat COVID-19 than it was 102 years ago. For example, antibiotics were not available in 1918 to prevent secondary bacterial infections (Gunderman, 2020).

This means that the world can and should address any negative aspects of AI. Not only that but humanity needs to use AI in a sustainable way; and also use AI in order to find solutions to achieve sustainability. Recent studies point to that direction (Chui et al., 2018; Vinuesa et al., 2020). Specifically, Chui et al. (2018), working on a McKinsey project, created a library of 160 cases covering 10 major domains of human life where AI can be used to address current social challenges. For example, within the domain of health and hunger challenges, AI can be applied for early stage diagnosis and optimize food distribution and early detection of diseases, such as diabetes or skin related problems. In the domain of information verification and validation, AI can provide significant help in preventing negative results, such as mob killings, caused by false and polarizing information.

Vinuesa et al. (2020) examine AI's potential impact on the 17 Sustainable Development Goals (SDGs) of the United Nations (UN) 2030 agenda. Specifically, they map all 169 targets of the 17 SDGs and they find that AI could have positive effects on 134 targets, while it may have negative effects in 69 targets -AI can have both positive and negative impact on the same target. An example is target 1.1.; AI can enable the decrease of poverty by identifying areas of poverty using satellite images and guide international action accordingly. However, AI requires special skills and training, thus increasing inequalities among the population (Vinuesa et al., 2020). Another potential negative aspect of $\mathrm{AI}$ is that its development takes place mainly in advanced countries, thus reflecting their needs and values, and not so much the needs and values of emerging ones (Vinuesa et al., 2020). However, most

\footnotetext{
${ }^{8}$ The 1918 flu is erroneously known as the 'Spanish flu' but it did not originate from Spain. During the 1st world war Spain was a neutral country, thus reporting objectively on the pandemic, whereas other countries such as Germany, France, Austria, the UK and the US did not report to avoid encouraging their enemies (Gunderman, 2020).
} 
technologies, such as cell phones and the internet, also were developed initially in advanced economies but developing countries also benefited. Cell phones and the internet have taken millions of people out of poverty (Sudan \& Lee, 2013).

A major way to prevent or limit any negative impacts and reimburse those who suffer from the negative impacts of AI is to apply AI within specific ethical standards and in a socially responsible way. Duane Windsor, a prominent scholar of corporate social responsibility, argues that firms will not refrain from substituting labor with AI, particularly if AI increases productivity and profits (Windsor, 2020). However, the point is not to close the door to AI in order to save jobs but to make sure those who lose their job can either find another or be reimbursed. Firms can do a lot in retraining and reskilling their employees. But, alleviating the negative effects of $\mathrm{AI}$ is not sole responsibility of firms (Windsor, 2020). Governments and civil society have a significant role to play in mitigating any AI disadvantages. International organizations, such as the OECD, political bodies, such as the European Commission, and universities are currently working on developing ethical standards for the implication of AI (Floridi \& Cowls, 2019). Education is a major pillar for training and educating as well as retraining and reskilling those most affected by the AI (Tsekeris, 2019). Ownership of AI and robotics is another important issue that needs to be handled responsibly (Windsor, 2020). Firms which gain the most from AI could donate an amount back to society to fund programs for those who lose their jobs. Even an AI tax or a robot tax can be levied in order to create a fund to reimburse those who may lose from the AI revolution (Zhang, 2019).

\section{Conclusions}

COVID-19 calls for global cooperation and synergies. AI benefits from COVID-19 as humanity accelerates AI applications and research to mitigate COVID-19 devastating impacts. Public administrations go digital to facilitate their citizens during lockdowns and social distancing. Some countries had already been digitized before COVID-19 hits. Others, such as Greece, have a unique opportunity to use COVID-19 to transform public administration and make it converge to most developed countries.

AI is the last technological revolution in a series of revolutions since $18^{\text {th }}$ century. COVID-19 brings this revolution closer as it has brought people all around the globe closer in order to fight the common enemy, the pandemic. Governments, the private sector, civil society, universities, and international organizations need not waste this unique opportunity of global cooperation against COVID-19 to also work toward more responsible AI. AI which does not leave parts of the population behind is the inclusive AI that benefits everyone creating only winners and no losers. Despite the highly disruptive effects the pandemic has caused, humanity can take the opportunity to use AI to combat not only the negative effects of the pandemic but also to improve the wellbeing of all and move closer to the fulfillment of the 17 SDGs. 


\section{References}

Acemoglu, D., \& Autor, D. (2012). What Does Human Capital Do? A Review of Goldin and Katz's The Race between Education and Technology. Journal of Economic Literature, 50(2), 426-463.

Acemoglu, D. \& Restrepo, P. (2015). The Race Between Man and Machine: Implications of Technology for Growth, Factor Shares and Employment. Mimeo.

Baldwin, R. (2016). The Great Convergence. Cambridge, MA: Harvard University Press.

Centers for Disease Control and Prevention. (2020). Similarities and differences between flu and COVID-19. https://www.cdc.gov/flu/symptoms/flu-vscovid19.htm

Chui, M., Harrysson, M., Manyika, J., Roberts, R., Chung, R., Nel, P., \& van Heteren, A. (2018). Applying artificial intelligence for social good. McKinsey Global Institute.

Chymis, A. (2020). Should we fear Artificial Intelligence? In Wolfgang, A. \& Stachowicz-Stanusch, A. (eds.) Artificial Intelligence and its Impact on Business (pp. 39-53). Charlotte, NC: Information Age Publishing.

Cimons, M. (2020). Reports of two promising covid-19 vaccines don't mean we 'magically,' quickly return to normal. Washington Post. 21 November. https://www.washingtonpost.com/health/covid-vaccine-masks-normallife/2020/11/20/b4ed16c8-2922-11eb-9b14-ad872157ebc9_story.html

Dreyfus, H. L., \& Dreyfus, S. E. (1986). Mind over Machine: The power of Human Intuition and Expertise in the Era of the Computer. New York: Free Press.

Dvorkin, M. A. (2020). Which jobs have been hit hardest by COVID-19? Federal Reserve Bank of St. Louis. 17 August.

https://www.stlouisfed.org/publications/regional-economist/third-quarter2020/jobs-hit-hardest-covid-19

Economist. (2020a). No vaccine for cruelty. The pandemic has eroded democracy and respect for human rights. 17 October.

Economist. (2020b). The pandemic is plunging million back into extreme poverty. 26 September.

Economist. (2020c). Which is the best market model? 12 September.

Economist. (2020d). Lockdowns could have long-term effects on children's health. 19 July.

Fernández-Macías, E. (2018). Automation, digitalisation and platforms: Implications for work and employment. Eurofound. Luxembourg: Publications Office of the European Union. 
Fjelland, R. (2020). Why general artificial intelligence will not be realized. Humanities and Social Sciences Communication, $7(10)$.

Floridi, L., \& Cowls, J. (2019). A unified framework of five principles for AI in society. Harvard Data Science Review, 1(1). https://doi.org/10.1162/99608f92.8cd550d1

Forbes, (2020). Covid-19 has accelerated digital transformation — with AI playing a key role. Forbes. 4 November.

https://www.forbes.com/sites/forbestechcouncil/2020/11/04/covid-19-hasaccelerated-digital-transformation---with-ai-playing-a-keyrole/?sh $=35501 \mathrm{a} 2 \mathrm{e} 5 \mathrm{a} 58$

Friedman, M. (2002/1962). Capitalism and Freedom. Fortieth anniversary edition. Chicago, IL: The University of Chicago Press.

Gunderman, R. (2020). 10 misconceptions about the $1918 \mathrm{flu}$, the 'greatest pandemic in history.' The Conversation, 17 March. https://theconversation.com/10misconceptions-about-the-1918-flu-the-greatest-pandemic-in-history-133994

Gurkaynak, G., Yilmaz, I., \& Haksever, G. (2016). Stifling artificial intelligence: Human perils. Computer Law \& Security Review, 32, 749-758.

Jacobs, J. (2020). How COVID-19 is accelerating the artificial intelligence revolution in healthcare. Pacific Prime. 4 August. https://www.pacificprime.com/blog/howcovid-19-is-accelerating-the-artificial-intelligence-revolution-in-healthcare.html

Holland, G. (2020). COVID-19: Accelerating digital transformation in uncertain times. KPMG. https://home.kpmg/au/en/home/insights/2020/05/covid-19-cio-insightsaccelerating-digital-transformation.html

Huang, M.-H., \& Rust, R.T. (2018). Artificial Intelligence in Service. Journal of Service Research, 21, 155-172.

Kande, M., \& M. Sönmez (2020). Don't fear AI. It will lead to long-term job growth. The World Economic Forum COVID Action Platform, 26 October. https://www.weforum.org/agenda/2020/10/dont-fear-ai-it-will-lead-to-long-termjob-growth/

Keynes, J. M. (1932). Economic Possibilities for our Grandchildren. In Essays in Persuasion (pp. 358-373). New York: Harcourt Brace. https://assets.aspeninstitute.org/content/uploads/files/content/upload/Intro and Section_I.pdf

Laguarta, J., Hueto, F., \& Subirana, B. (2020). COVID-19 Artificial Intelligence Diagnosis using only Cough Recordings. IEEE Open Journal of Engineering in Medicine and Biology. https://digitalreality.ieee.org/images/files/pdf/COVID-AIDiagnosis-using-Cough-Recordings.pdf 
Manyika, J., Lund, S., Chui, M., Bughin, J., Woetzel, J., Batra, P., Ko, R., \& Sanghvi, S. (2017). Jobs Lost, Jobs Gained: Workforce transitions in a time of automation. McKinsey Global Institute.

Manyika, J., \& Sneader, K. (2018). AI, Automation, and the future of work: ten things to solve for. McKinsey Global Institute.

McCloskey, D. N. (2016). Bourgeois equality: How ideas, not capital or institutions, enriched the world. Chicago. IL: University of Chicago Press.

Mokyr, J., Vickers, C., \& Ziebarth, N. L. (2015). The history of technological anxiety and the future of economic growth: Is this time different? Journal of Economic Perspectives, 29(3), 31-50.

Nash, V., \& Enyon, R. (2020). Coronavirus school closures impact 1.3 billion children and remote learning is increasing inequality. The Conversation, 18 May. https://theconversation.com/coronavirus-school-closures-impact-1-3-billionchildren-and-remote-learning-is-increasing-inequality-138656

Nguyen, T. T. (2020). Artificial Intelligence in the Battle against Coronavirus (COVID19): A Survey and Future Research Directions. Preprint: https://arxiv.org/abs/2008.07343

Peralta-Alva A., \& Roitman, A. (2018). Technology and the future of work. International Monetary Fund, working paper 18/207.

Pinker, S. (2018). Enlightenment now: the case for science, reason, humanism, and progress. New York: Penguin.

Rao, A., \& Firth-Butterfield, K. (2020). 3 ways COVID-19 is transforming advanced analytics and AI. The World Economic Forum COVID Action Platform. 20 July. https://www.weforum.org/agenda/2020/07/3-ways-covid-19-is-transformingadvanced-analytics-and-ai/

Repucci, S., \& Slipowitz, A. (2020). Democracy under lockdown: The Impact of COVID19 on the Global Struggle for Freedom (Special Report). Washington: Freedom House.

Rosling, H., Rosling O., \& Rosling-Rönnlund, A. (2018). Factfulness: Ten Reasons We're Wrong About the World--and Why Things Are Better Than You Think. New York: Flatiron Books.

Sneader, K., \& Sternfels, B. (2020). From surviving to thriving: Reimagining the postCOVID-19 return. McKinsey Global Institute.

Stanford report. (2016). Artificial Intelligence and life in 2030 (Report of the 2015 study panel). https://ai100.stanford.edu/sites/g/files/sbiybj9861/f/ai100report10032016fnl singl es.pdf 
Stewart, I., De, D., \& Cole, A. (2015). Technology and People: The Great Job-Creating Machine. London: Deloitte.

Stone, M. (2020). Digital: It is not the future, it is today. KPMG. https://home.kpmg/xx/en/home/industries/government-public-sector/the-newreality-for-government/digital-is-not-the-future-it-is-today.html

Strelkova, O.; Pasichnyk, O. (2017). Three Types of Artificial Intelligence. Khmelnitsky, Ukraine: Khmelnitsky National University.

http://eztuir.ztu.edu.ua/bitstream/handle/123456789/6479/142.pdf?sequence=1\&i sAllowed $=y$

Sudan, R., \& Lee, S. S. (2013). The role of mobile devices in fighting poverty. World Bank - Digital Development. https://blogs.worldbank.org/digitaldevelopment/role-mobile-devices-fighting-poverty

Tsekeris, C. (2019). Surviving and thriving in the Fourth Industrial Revolution: Digital skills for education and society. Homo Virtualis, 2(1), 34-42.

https://doi.org/10.12681/homvir.20192

Vinuesa, R., Azizpour, H., Leite, I., Balaam, M., Dignum, V., Domisch, S., Felländer, A., Langhans, S., D., Tegmark, M., \& Nerini, F.F. (2020). The role of artificial intelligence in achieving the Sustainable Development Goals. Nature Communications, 11(233). https://www.nature.com/articles/s41467-019-14108-y

Windrum, P. (2008). Innovation and entrepreneurship in public services. In Windrum, P., Koch, P. (eds.) Public Sector Services - Entrepreneurship, Creativity and Management (pp. 3-20). Cheltenham: Edward Elgar.

Windsor, D. (2020). An AI and robotic world: which implications for social responsibility? In Wolfgang, A. \& Stachowicz-Stanusch, A. (eds.) Artificial Intelligence and its Impact on Business (pp. 117-141). Charlotte, NC: Information Age Publishing.

World Bank. (2020a). COVID-19 to add as many as 150 million extreme poor by 2021 (Press release No: 2021/024/DEC-GPV), 7 October. https://www.worldbank.org/en/news/press-release/2020/10/07/covid-19-to-addas-many-as-150-million-extreme-poor-by-2021

World Bank. (2020b). Understanding Poverty: Overview, 7 October. https://www.worldbank.org/en/topic/poverty/overview

World Health Organization. (2020). Considerations for school-related public health measures in the context of COVID-19 (Annex to Considerations in adjusting public health and social measures in the context of COVID-19), 14 September. https://apps.who.int/iris/rest/bitstreams/1303058/retrieve 
Wuest, Th., Kusiak, A., Dai, T., \& Sridhar, T. R. (2020). Impact of COVID-19 on Manufacturing and Supply Networks - The Case for AI-Inspired Digital Transformation, 5 May. https://ssrn.com/abstract=3593540.

Zhang, P. (2019). Automation, wage inequality and implications of a robot tax. International Review of Economics \& Finance, 59, 500-509.

\section{Notes on Contributors}

Athanasios Chymis (Ph.D.) is a Senior Research Fellow at the Centre of Planning and Economic Research (KEPE) in Athens, Greece. His work focuses on the interface between Ethics and Economics and he investigates the role of Institutions in shaping a healthy competitive environment which, in turn, affects the relationship between Ethics and Economics. Moreover, he conducts research on Social Responsibility and looks at ways to infuse the concept of Responsibility in public administration as well as in all organizations of both private and public sector. His work appears in scientific journals and books of multiple publishing houses including, Springer, Greenleaf, Information Age Publishing, etc., while he holds regular columns at KEPE's journal Greek Economic Outlook. 